\title{
Tigecycline use in serious nosocomial infections: a drug use evaluation
}

\author{
Matteo Bassetti ${ }^{*}$, Laura Nicolini, Ernestina Repetto, Elda Righi, Valerio Del Bono, Claudio Viscoli
}

\begin{abstract}
Background: Tigecycline is a novel antibiotic with activity against multidrug resistant bacteria. The aim of this study was to assess the efficacy of tigecycline use in serious hospital-acquired infections (HAl)

Case presentation: Prospective observational study of tigecycline use was conducted in a 1500 beds university hospital. From January 1, 2007 and January 31, 2010, 207 pts were treated with tigecycline for the following indications: intra-abdominal, pneumonia, bloodstream and complicated skin and soft tissue infections and febrile neutropenia. The therapy was targeted in 130/207 (63\%) and empirical in 77/207 (37\%) patients. All bacteria treated were susceptible to tigecycline. Median duration of tigecycline therapy was 13 days (range, 6-28). Clinical success was obtained in 151/207 (73\%) cases, with the highest success rate recorded in intra-abdominal infections [81/99 (82\%)]. Microbiological success was achieved in 100/129 (78\%) treated patients. Adverse clinical events were seen in 16/207 patients (7.7\%):
\end{abstract}

Conclusions: Considering the lack of data on tigecycline for critically ill patients, we think that the reported data of our clinical experience despite some limitations can be useful for clinicians.

\section{Background}

The management of hospital-acquired bacterial infections is becoming a significant challenge for health care providers because of the increased prevalence of multidrug-resistant (MDR) bacteria like methicillin-resistant Staphylococcus aureus (MRSA), vancomycin-resistant Enterococcus spp. (VRE), Acinetobacter baumannii, Klebsiella pneumoniae, carbapenemase -producing Enterobacteriaceae, and extended-spectrum beta-lactamase (ESBL)-producing Enterobacteriaceae. Increased morbidity and mortality, duration of hospitalization, and medical care costs are all associated with MDR organisms [1]. Delay of appropriate empiric antimicrobial therapy is known to increase morbidity and mortality among affected patients and inadequate therapy has been found to be associated with excess mortality and increased duration of hospitalization [2]. There is a high rate of resistance to commonly used antimicrobial agents, including beta-lactams (penicillins and cephalosporins), fluoroquinolones, aminoglycosides and

\footnotetext{
* Correspondence: matteo.bassetti@hsanmartino.it Infectious Diseases Division, San Martino Hospital and University of Genoa
} School of Medicine, Genoa, Italy

(0) 2010 Bassetti et al; licensee BioMed Central Ltd. This is an Open Access article distributed under the terms of the Creative Commons Attribution License (http://creativecommons.org/licenses/by/2.0), which permits unrestricted use, distribution, and reproduction in any medium, provided the original work is properly cited. glycopeptides, which may reduce the effectiveness of these drugs.

Tigecycline is a new glycylcycline antibitiotic that has come into clinical use at a critical time and demonstrates in vitro activity against a wide range of bacteria $[3,4]$. Tigecycline has been approved by the Food and Drug Administration (FDA) and the European Medicines Agency (EMEA) for the treatment of complicated intra-abdominal and skin and soft tissue infections $[5,6]$. Besides, FDA recently approved it for the treatment of community-acquired pneumonia [7]. However, the role of tigecycline in the treatment of infections due to MDR bacteria remains undefined.

We conducted a prospective study to determine both clinical and microbiological outcomes of patients treated with tigecycline for serious hospital-acquired infections (HAI).

\section{Methods}

The study was conducted at the San Martino Hospital, a 1500 -bed, academic, tertiary care medical centre in Genoa (Italy). All adult subjects admitted to the hospital who received $\geq 48 \mathrm{~h}$ of treatment with tigecycline between January 1, 2007 and January 31, 2010 for 
treatment of HAI were enrolled. All patients received standard FDA and EMEA -approved dosage of tigecycline (initial loading dose of $100 \mathrm{mg}$, followed by $50 \mathrm{mg}$ administered intravenously every $12 \mathrm{~h}$ ). Identification and susceptibility testing of bacterial isolates were performed by standard techniques, with the use of a semi-automated system (Vitek 2; bioMerieux). Clinical data was collected from medical records and included age, sex, comorbidities, APACHE II score, clinical diagnosis, microbiologic isolate identification with antibiotic susceptibility, concomitant antibiotics, indication for tigecycline use, duration of tigecycline treatment and adverse clinical events.

Established criteria were used to define an hospitalacquired infection [8]. Secondary peritonitis was defined as a result of spillage of gut organisms through a physical hole in the gastrointestinal tract or through a necrotic gut wall and included intra-abdominal abscess (including liver, spleen and pancreatic), perforated diverticulitis complicated by abscess formation or fecal contamination; complicated cholecystitis with evidence of perforation, empyema, or gangrene; perforation of a gastric or duodenal ulcer; purulent peritonitis or peritonitis associated with fecal contamination; or perforation of the large or small intestine with abscess or fecal contamination; tertiary peritonitis was defined a peritonitis in a critically ill patient which persists or recurs at least $48 \mathrm{~h}$ after apparently adequate management of primary or secondary peritonitis. Empirical use of tigecycline was defined as the administration of treatment to a patient with signs and symptoms of infection without an identified source or a specific microbiological isolate. Targeted therapy was defined as the antibiotic administration in presence of an identified isolate.

Clinical response at the end of treatment was defined as positive response (partial or complete improvement of signs/symptoms of infection), negative response (no improvement or deterioration of signs/symptoms of infection), or uncertain response. Microbiological response was defined as positive response (sterile culture results during or after the course of antibiotic therapy), negative response (persistent identification of the same organism for 3 days after initiation of antibiotic treatment), or not documented response. The overall response was considered positive if any of the positive criteria of microbiological response were met.

The study was approved by the local institutional review board (Comitato Etico, Azienda Ospedaliera Universitaria San Martino, Genova, Italy) and patient consent was not required because of the observational nature of this study.

\section{Cases presentation}

Two hundred and seven patients received tigecycline therapy for $\geq 48 \mathrm{~h}$ within our facility during the defined study
Table 1 Clinical characteristics of patients at start of tigecycline

\begin{tabular}{lc}
\hline & $n, 207$ \\
\hline Gender, $n$ (\%) & $118(57)$ \\
\hline Age, yrs & 63 \\
Median & $14-89$ \\
Range & \\
\hline Apache II score & $21 \pm 8.8$ \\
Mean ( \pm SD) & $8-458-45$ \\
Range & $83(40)$ \\
\hline Admitted to ICU, $n(\%)$ & \\
\hline Co-morbid conditions, $n$ (\%) & $79(38)$ \\
Solid tumor & $50(24)$ \\
Hematologic malignancy & $48(23)$ \\
Diabetes mellitus & $29(14)$ \\
Neutropenia (< 500 mm3) &
\end{tabular}

period for the treatment of HAI. The clinical characteristics of the patients were reported in Table 1. Tigecycline was mainly used in the following wards: general surgery, oncology, haematology and intensive care. The therapy was targeted in 130/207 (63\%) and empirical in 77/207 $(37 \%)$ patients. All bacteria treated were susceptible to tigecycline. Median duration of tigecycline therapy was 13 days (range, 6-28) (table2). In table 2 type of infections and clinical efficacy of tigecycline are detailed. Table 3 details bacterial isolates and eradication rates. In 161/207 (78\%) cases tigecycline was used as monotherapy, while $46 / 207$ (22\%) patients received tigecycline as part of a combination therapy, mainly associated with colistin (19/ 46; 41\%), meropenem (11/46; 24\%), amikacin (9/46; 20\%), or ciprofloxacin $(7 / 46 ; 15 \%)$. Clinical success was obtained in $151 / 207$ (73\%) cases, with the highest success rate recorded in intra-abdominal infections [81/99 (82\%)]. Microbiological success was achieved in 100/129 (78\%) treated patients. Adverse clinical events were seen in 16/ 207 patients (7.7\%): 5 (2.4\%) experienced mild nausea, and 12 (5.8\%) experienced nausea and vomiting, while 7 (3.4\%) experienced an increasing in liver enzymes. Only 4 (1.9\%) of the total 207 patients experienced diarrhoea on tigecycline, all of whom were negative for $\mathrm{C}$. difficile toxin in stools. Only one patient interrupted tigecycline in reason of adverse effects (profuse vomiting and nausea).

\section{Conclusions}

We described 207 patients who received tigecycline under real-life conditions of daily clinical practice for empiric or targeted treatment of serious HAI. Tigecycline was used to treat a variety of infections, including many that were not indicated in official FDA and EMEA labelling for tigecycline. Despite the fact that most of 
Table 2 Type of infections, duration of treatment and clinical efficacy of tigecycline

\begin{tabular}{|c|c|c|c|c|}
\hline Type of infections & $n(\%)$ & $\begin{array}{c}\text { Duration of treatment, days } \\
\text { Median (range) }\end{array}$ & $\begin{array}{c}\text { Clinical efficacy } \\
n(\%)\end{array}$ & $\begin{array}{c}\text { Clinical failure } \\
n(\%)\end{array}$ \\
\hline Secondary peritonitis & $46(22)$ & $9(6-18)$ & $40(88)$ & $6(12)$ \\
\hline Tertiary peritonitis & $41(20)$ & $15(11-28)$ & $32(78)$ & $9(22)$ \\
\hline Other abdominal infections & $12(6)$ & $11(7-17)$ & $5(42)$ & $7(58)$ \\
\hline Pneumonia ( HAP, HCAP, VAP) & $27(13)$ & $12(8-21)$ & $18(67)$ & $9(33)$ \\
\hline Pneumonia and bloodstream infections & $29(14)$ & $17(13-24)$ & $19(66)$ & $10(34)$ \\
\hline Bloodstream infections & $23(11)$ & $15(12-18)$ & $16(70)$ & $7(30)$ \\
\hline Complicated skin and soft tissue infections & $17(8)$ & $11(7-18)$ & $13(76)$ & $4(24)$ \\
\hline Empiric use in neutropenic & $12(6)$ & $14(9-17)$ & $7(58)$ & $5(42)$ \\
\hline Total & $207(100)$ & & $151(73)$ & $56(27)$ \\
\hline
\end{tabular}

HAP: hospital acquired pneumonia, HCAP: health care associated pneumonia, VAP: ventilator associated pneumonia.

the patients were critically ill and requiring ICU care or they had high APACHE II scores at the time of tigecycline administration, the overall clinical outcomes were good. The patients analyzed in this prospective study constitute the biggest relevant cohort. Successful clinical response rates of $82 \%$ were recorded for intra-abdominal infections and $78 \%$ for complicated skin and soft tissue infections with an overall successful clinical response of $73 \%$. The mean clinical response rate was lower in patients with febrile neutropenia, pneumonia and bacteremia $(58 \%, 67 \%$ and $70 \%$, respectively). The population represented in this study included a significantly higher proportion of seriously ill patients which was not captured in the Phase 3 registration trials for each therapeutic indication. In a pooled analysis of two Phase 3 double-blind trials of tigecycline versus imipenem-cilastatin in patients with complicated intra-abdominal infection, the mean APACHE II score of tigecycline-treated patients was 6.3, and only $3.5 \%$ of them had an APACHE II score higher than 15; an APACHE II score of more than 20 was an exclusion criterion in those studies [5]. The population treated in our study mirrors the typical patients with complicated HAI and significantly higher APACHE II scores (mean score of 21) and thus higher disease severity and the data confirm similar recent experiences $[9,10]$. In addition, the majority of the patient population experienced co-morbidities leading to a higher risk of infections with MDR bacteria.

In approximately half of the patients, complicated intra-abdominal infections were involved, including MRSA and Enterococcus spp infections. We observed a remarkably high proportion of enterococcal infections and among them tigecycline had a success rate of $76 \%$, similar to the microbiological efficacy obtained against MRSA (80\%). Regarding the anti-Gram-negative efficacy, tigecycline confirms its effectiveness especially for $E$. coli (81\%) and A. baumannii (69\%). This data confirms recent similar experiences reported [11-14]. The majority of patients received tigecycline in monotherapy and only $22 \%$ of patients were treated with tigecycline in combination with other broad-spectrum antibiotics to expand the range of activity against $P$. aeruginosa.

In this non-comparative trial, tigecycline appeared safe and effective in the treatment of serious HAI caused by resistant bacteria. The data from this study is consistent with larger pivotal studies of tigecycline treatment of serious infections [5-7]. For these reasons, tigecycline may be useful as an addition to the clinician's antimicrobial therapy options for difficult-to-treat resistant pathogens associated with serious nosocomial infections and also as part of an overall infection control and pharmacy intervention as suggested in the current guidelines [15].

Table 3 Bacterial isolates treated with tigecycline and eradication rate

\begin{tabular}{|c|c|c|c|}
\hline Bacterial isolates & $n(\%)$ & $\begin{array}{c}\text { Microbiological efficacy } \\
n(\%)\end{array}$ & $\begin{array}{c}\text { Microbiological failure } \\
n(\%)\end{array}$ \\
\hline Enterococcus faecium & $31(24)$ & $22 / 31(71)$ & $9 / 31(29)$ \\
\hline Escherichia coli & $26(20)$ & $21 / 26(81)$ & $5 / 26(19)$ \\
\hline Methicillin-resistant Staphylococcus aureus & $20(15)$ & $16 / 20(80)$ & $4 / 20(20)$ \\
\hline Acinetobacter baumannii & $16(12)$ & $11 / 16(69)$ & $5 / 16(31)$ \\
\hline Klebsiella pneumoniae & $15(12)$ & 13/15 (89) & $2 / 15(11)$ \\
\hline Enterobacter cloacae & $10(8)$ & $8 / 10(80)$ & $2 / 10(20)$ \\
\hline Enterococcus faecalis & $6(5)$ & $6 / 6(100)$ & $0 / 6$ \\
\hline Others & $5(4)$ & $3 / 5(60)$ & $2 / 5(40)$ \\
\hline Total & 129 & 100/129 (78) & $29 / 129(22)$ \\
\hline
\end{tabular}


The results should be viewed as purely descriptive, as this was an observational, prospective analysis of data from 207 patients who had received tigecycline in our hospital and no control group of patients (treated with drugs other than tigecycline) was analysed in this assessment. Considering the lack of data on newly approved antimicrobial agents for critically ill patients, we think that the reported data of our clinical experience with tigecycline, despite the limitations discussed can be useful for clinicians.

\section{Acknowledgements}

The study was conducted independently of the funding agencies and pharmaceutical companies.

\section{Authors' contributions}

MB: Data acquisition, data/statistical analyses, drafting the manuscript; LN: Sample collection, drafting the manuscript, critically revising for medical content; ER: Sample collection, critically revising for medical content; ER: Study design and conception, critically revising for medical content; VD: Data acquisition, data analyses; CV: Study design, conception and coordination; All authors contributed to writing of the final manuscript; All authors read and approved the final manuscript.

\section{Competing interests}

Matteo Bassetti have received speaker's honoraria and/or research grant from: Pfizer, Astellas, MSD, Novartis, Bayer, Aventis, GSK and Astra Zeneca. The other authors declare that they have no competing interests.

Received: 16 March 2010 Accepted: 29 September 2010

Published: 29 September 2010

\section{References}

1. Siegel JD, Rhinehart $E$, Jackson M, Chiarello L: Healthcare Infection Control Practices Advisory Committee. Management of multidrug-resistant organisms in health care settings, 2006. Am J Infect Control 2007, 35(10 Suppl 2), S165YS193.

2. Hyle EP, Lipworth AD, Zaoutis TE, Nachamkin I, Bilker WB, Lautenbach E: Impact of inadequate initial antimicrobial therapy on mortality in infections due to extended-spectrum beta-lactamase-producing enterobacteriaceae: variability by site of infection. Arch Intern Med 2005, 165:1375-1380.

3. Bratu S, Tolaney P, Karumudi U, Quale J, Mooty M, Nichani S, Landman D: Carbapenemase-producing Klebsiella pneumoniae in Brooklyn, NY: molecular epidemiology and in itro activity of polymyxin $B$ and other agents. J Antimicrob Chemother 2005, 56:128-32.

4. Hawkey P, Finch R: Tigecycline: in-vitro performance as a predictorof clinical efficacy. Clin Microbiol Infect 2007, 13:354-62.

5. Babinchak T, Ellis-Grosse E, Dartois N, Rose GM, Loh E, Tigecycline 301 Study Group; Tigecycline 306 Study Group: The efficacy and safety of tigecycline for the treatment of complicated intraabdominal infections: analysis of pooled clinical trial data. Clin Infect Dis 2005, 41:S354-67.

6. Ellis-Grosse EJ, Babinchak T, Dartois N, Rose G, Loh E, Tigecycline 300 cSSSI Study Group; Tigecycline 305 cSSSI Study Group: The efficacy and safety of tigecycline in the treatment of skin and skin-structure infections: results of 2 double-blind phase 3 comparison studies with vancomycinaztreonam. Clin Infect Dis 2005, 41:\$341-53.

7. Tanaseanu C, Milutinovic S, Calistru PI, Strausz J, Zolubas M, Chernyak V, Dartois N, Castaing N, Gandjini H, Cooper CA, 313 Study Group: Efficacy and safety of tigecycline versus levofloxacin for community-acquired pneumonia. BMC Pulm Med 2009, 9:44.

8. Garner JS, Jarvis WR, Emori TG, Horan TC, Hughes JM: CDC definitions for nosocomial infections, 1988. Am J Infect Control 1988, 16:128-40.

9. Swoboda S, Ober M, Hainer C, Lichtenstern C, Seiler C, Wendt C, HoppeTichy T, Büchler M, Weigand MA: Tigecycline for the treatment of patients with serious sepsis or septic shock: a drug use evaluation in a surgical intensive care unit. J Antimicrob Chemother 2008, 61:729-33.
10. Chemaly RF, Hanmod SS, Jiang Y, Rathod DB, Mulanovich V, Adachi JA, Rolston KV, Raad II, Hachem RY: Tigecycline Use in Cancer Patients With Serious Infections A Report on 110 Cases From a Single Institution. Medicine 2009, 88:211-220.

11. Poulakou G, Kontopidou FV, Paramythiotou E, Kompoti M, Katsiari M, Mainas E, Nicolaou C, Yphantis D, Antoniadou A, Trikka-Graphakos E, Roussou Z, Clouva P, Maguina N, Kanellakopoulou K, Armaganidis A Giamarellou $\mathrm{H}$ : Tigecycline in the treatment of infections from multi-drug resistant gram-negative pathogens. J Infect 2009, 58:273-284.

12. Schafer JJ, Goff DA, Stevenson KB, Mangino JE: Early experience with tigecycline for ventilator-associated pneumonia and bacteraemia caused by multidrug-resistant Acinetobacter baumannii. Pharmacother 2007, 27:980-7.

13. Gallagher JC, Rouse HM: Tigecycline for the treatment of Acinetobacter infections: a case series. Ann Pharmacother 2008, 42:1188-94.

14. Karageorgopoulos DE, Kelesidis T, Kelesidis I, Falagas ME: Tigecycline for the treatment of multidrug-resistant (including carbapenem-resistant) Acinetobacter infections: a review of the scientific evidence. J Antimicrob Chemother 2008, 62:45-55.

15. Dellit TH, Owens RC, McGowan JE Jr, Gerding DN, Weinstein RA, Burke JP, Huskins WC, Paterson DL, Fishman NO, Carpenter CF, Brennan PJ, Billeter M, Hooton TM, Infectious Diseases Society of America; Society for Healthcare Epidemiology of America: Infectious Diseases Society of America and the Society for Healthcare Epidemiology of America guidelines for developing an institutional program to enhance antimicrobial stewardship. Clin Infect Dis 2007, 44:159-77.

Pre-publication history

The pre-publication history for this paper can be accessed here: http://www.biomedcentral.com/1471-2334/10/287/prepub

doi:10.1186/1471-2334-10-287

Cite this article as: Bassetti et al:: Tigecycline use in serious nosocomial infections: a drug use evaluation. BMC Infectious Diseases 2010 10:287.

\section{Submit your next manuscript to BioMed Central and take full advantage of:}

- Convenient online submission

- Thorough peer review

- No space constraints or color figure charges

- Immediate publication on acceptance

- Inclusion in PubMed, CAS, Scopus and Google Scholar

- Research which is freely available for redistribution 